BNL-101169-2013-CP

\title{
Study of the Diffusion of Te Inclusions in CdZnTe Nuclear Detectors in Post-Growth Annealing
}

\author{
Ge Yang \\ Presented at the 2012 IEEE Nuclear Science Symposium and Medical Imaging \\ Anaheim, CA \\ October 29 - November 3, 2012
}

June 2013

\author{
Nonproliferation and National Security Department \\ Brookhaven National Laboratory \\ P.O. Box 5000 \\ Upton, New York 11973 \\ www-bnl.gov
}

\begin{abstract}
Notice: This manuscript has been authored by employees of Brookhaven Science Associates, LLC under Contract No. DE-AC02-98CH10886 with the U.S. Department of Energy. The publisher by accepting the manuscript for publication acknowledges that the United States Government retains a non-exclusive, paid-up, irrevocable, world-wide license to publish or reproduce the published form of this manuscript, or allow others to do so, for United States Government purposes.

This preprint is intended for publication in a journal or proceedings. Since changes may be made before publication, it may not be cited or reproduced without the author's permission.
\end{abstract}




\section{DISCLAIMER}

This report was prepared as an account of work sponsored by an agency of the United States Government. Neither the United States Government nor any agency thereof, nor any of their employees, nor any of their contractors, subcontractors, or their employees, makes any warranty, express or implied, or assumes any legal liability or responsibility for the accuracy, completeness, or any third party's use or the results of such use of any information, apparatus, product, or process disclosed, or represents that its use would not infringe privately owned rights. Reference herein to any specific commercial product, process, or service by trade name, trademark, manufacturer, or otherwise, does not necessarily constitute or imply its endorsement, recommendation, or favoring by the United States Government or any agency thereof or its contractors or subcontractors. The views and opinions of authors expressed herein do not necessarily state or reflect those of the United States Government or any agency thereof. 


\title{
Study of the Diffusion of Te Inclusions in CdZnTe Nuclear Detectors in Post-Growth Annealing
}

\author{
Stephen U. Egarievwe, Member, IEEE, Aaron L. Adams, Mebougna L. Drabo, Marcus D. Ashford, Rodney Pinder, \\ Dominique E. Jones, Aschalew Kassu, Wing Chan, Ge Yang, Giuseppe S. Camarda, \\ Aleksey E. Bolotnikov, Member, IEEE, Ralph B. James, Fellow, IEEE
}

\begin{abstract}
Despite immense endeavor invested in optimizing the crystal growth parameters and the post growth improvement methodologies proposed by numerous studies, there are still unresolved shortcomings of CdZnTe crystals to produce commercial-grade CdZnTe detectors. Post-growth thermal annealing under $\mathrm{Zn}$, Te, or $\mathrm{Cd}$ vapor overpressure at various temperature have been the approach attempted to improve the crystallinity of CdZnTe crystals. This paper presents results of post growth annealing of CdZnTe detectors that shows both reduction in the sizes of Te inclusions and the migration of the inclusions towards the high-temperature side of the crystal. Two set of annealing experiments were made. The first is annealing under $\mathrm{Cd}$ vapor overpressure in vacuum at $600{ }^{\circ} \mathrm{C}$ for 45 minutes at a temperature gradient of $10{ }^{\circ} \mathrm{C} / \mathrm{cm}$. The second set of $\mathrm{CdZnTe}$ post-growth annealing experiments was carried out at $700{ }^{\circ} \mathrm{C}$ CdZnTe annealing temperature with the Cadmium temperature at $650{ }^{\circ} \mathrm{C}, 30$ minutes annealing time, and temperature gradient of $10{ }^{\circ} \mathrm{C} / \mathrm{cm}$. The reduction in the sizes of $\mathrm{Te}$ inclusions ranges from $8 \%$ to $38 \%$.
\end{abstract}

\section{INTRODUCTION}

$\mathrm{R}_{\mathrm{s}}^{\mathrm{o}}$ OOM-TEMPERATURE semiconductor nuclear detector grade materials are desired to have high resistivity (low dark current), high atomic number (good stopping power), good carrier mobility-lifetime product, $\mu \tau$, (for better collection of charge), high band-gap, high crystallinity (uniformity of response), and room temperature performance. Cadmium Zinc Telluride (CdZnTe) is one of the most investigated materials as a wide band-gap semiconductor crystal for nuclear radiation detection [1]-[4], nuclear medicine [5], medical imaging [6], [7], and in the field of astrophysics for measurement of celestial gamma-ray photons [7]. Despite immense endeavor invested in optimizing the crystal growth parameters and the post growth improvement methodologies proposed by numerous studies, there are still

Manuscript received November 16, 2012. This work was supported in part by the U.S. Department of Homeland Security (DHS) under Grant No. 2012DN-077-ARI065-02; by the National Science Foundation (NSF) under Grant No. 1140059; by the U.S. Nuclear Regulatory Commission (NRC) under Grant No. NRC-27-10-514; and by the U.S. Department of Energy (DOE) through Brookhaven National Laboratory (BNL).

S. U. Egarievwe, A. L. Adams, M. L. Drabo, R. Pinder, D. E. Jones, A. Kassu, and W. Chan are with the Engineering, Construction Management and Industrial Technology Department, Alabama A\&M University, Huntsville, AL 35810-1015 USA (e-mail: stephen.egarievwe@aamu.edu).

M. D. Asford is with the Mechanical Engineering Department, The University of Alabama, Tuscaloosa, AL 35487 USA.

G. Yang, G. S. Camarda, A. E. Bolotnikov, and R. B. James are with the Department of Nonproliferation and National Security, Brookhaven National Laboratory, Upton, NY 11973-5000 USA (e-mail: rjames@bnl.gov). unresolved shortcomings of CdZnTe crystals to produce commercial-grade CdZnTe detectors [8]. Post-growth thermal annealing under $\mathrm{Zn}$, Te, or Cd vapor overpressure at various temperature have been the approach attempted to improve the crystallinity of CdZnTe crystals. One of the widely reported defects is defect associated with Cadmium vacancy created during the crystal growth process. To compensate the $\mathrm{Cd}$ vacancy created, eliminate tellurium inclusions and improve the overall performance of the crystal, post-growth thermal annealing of CdZnTe crystals under Cd vapor overpressure has been a widely accepted practice [1]-[4]. To our knowledge, Wanwan et al is the first to report the theoretical and experimental findings on the effect of Cd-diffusion thermal annealing on the resistivity of CdZnTe crystals (9). Based on this study, the average values of Cd self-diffusion coefficients of $\mathrm{Cd}_{0.9} \mathrm{Zn}_{0.1}$ Te crystal annealed at 1073,973 , and $873 \mathrm{~K}$ are found to be $1.464 \times 10^{-10}, 1.085 \times 10^{-11}$, and $4.167 \times 10^{-13}$ $\mathrm{cm} 2 / \mathrm{s}$. Recently, Fochuk et al. reported a promising result on elimination of Te inclusion in CdZnTe crystals by short term thermal annealing under $\mathrm{Cd}, \mathrm{Zn}$, and Te-over pressure and the corresponding resistivity of the crystal for a range of annealing temperature [10].

\section{EXPERIMENT}

CdZnTe crystals with detector-grade quality grown by Northrop Grumman using the Bridgman furnace method were used. The crystals were cut approximately $5 \times 5 \times 5 \mathrm{~mm}^{3}$. The surfaces of the CdZnTe slices used for the experiments were prepared by mechanical polishing, using a series of $\mathrm{Al}_{2} \mathrm{O}_{3}$ powders grades, decreasing in size from 5.0 to 0.1 microns as necessary. The material removed in this procedure $(\sim 200 \mu \mathrm{m}$ by mechanical polishing, $\sim 100 \mu \mathrm{m}$ by etching) was sufficient to remove all surface damage caused by sawing the slices from the wafer. Next, the CdZnTe crystals were etched using a $2 \%$ Br-methanol solution.

In the experimental procedure, infrared images of the samples were taken before and after annealing. The samples are marked to track the locations and orientations of the Te inclusion being studied. Samples were annealed under $\mathrm{Cd}$ vapor overpressure and in vacuum at $600{ }^{\circ} \mathrm{C}$ for 45 minutes at a temperature gradient of $10{ }^{\circ} \mathrm{C} / \mathrm{cm}$. A second set CdZnTe post-growth annealing experiments was carried for the following annealing parameters: $700{ }^{\circ} \mathrm{C} \mathrm{CdZnTe}$ annealing temperature, Cadmium temperature at $650{ }^{\circ} \mathrm{C}, 30$ minutes annealing time, and temperature gradient of $10{ }^{\circ} \mathrm{C} / \mathrm{cm}$. 


\section{RESULTS}

Figure 1 shows the infrared images of the same region of a CdZnTe crystal before annealing and for the first and second annealing cycles (at $600{ }^{\circ} \mathrm{C}, 45$ minutes and temperature gradient of $10{ }^{\circ} \mathrm{C} / \mathrm{cm}$ for each cycle).

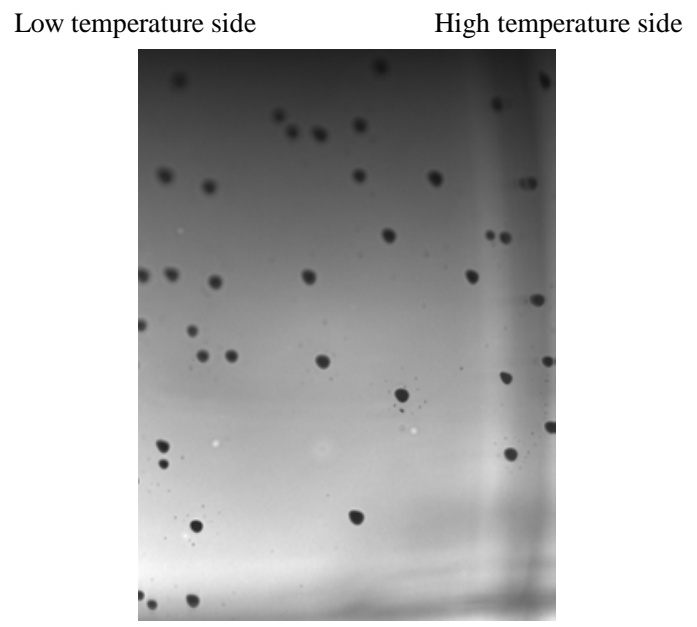

(a) Before annealing

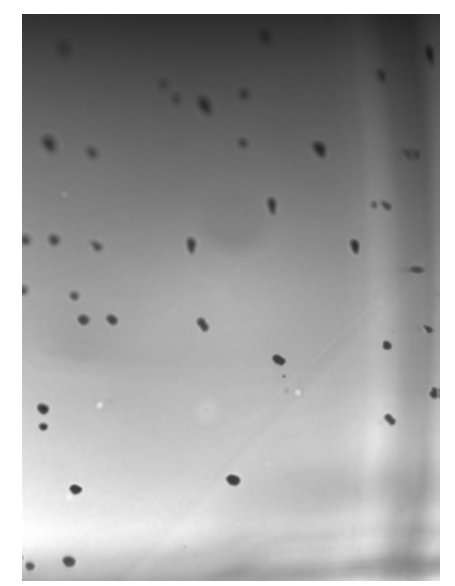

(b) First annealing at $600{ }^{\circ} \mathrm{C}$ for 45 minutes

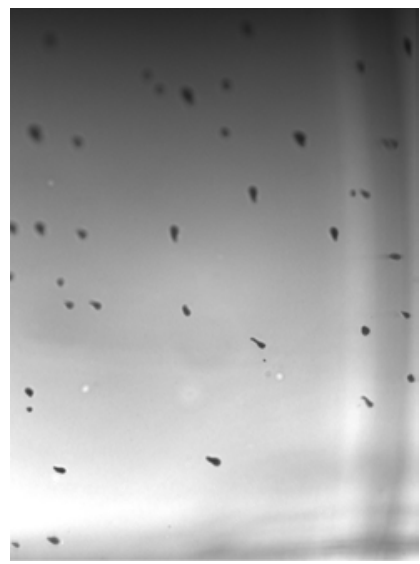

(c) Second annealing at $600{ }^{\circ} \mathrm{C}$ for 45 minutes

Fig. 1. Infrared images comparing Te inclusions sizes and locations of the same region in the CdZnTe crystal before annealing, and for the first and second annealing cycles (at $600{ }^{\circ} \mathrm{C}$ for 45 minutes for each cycle).

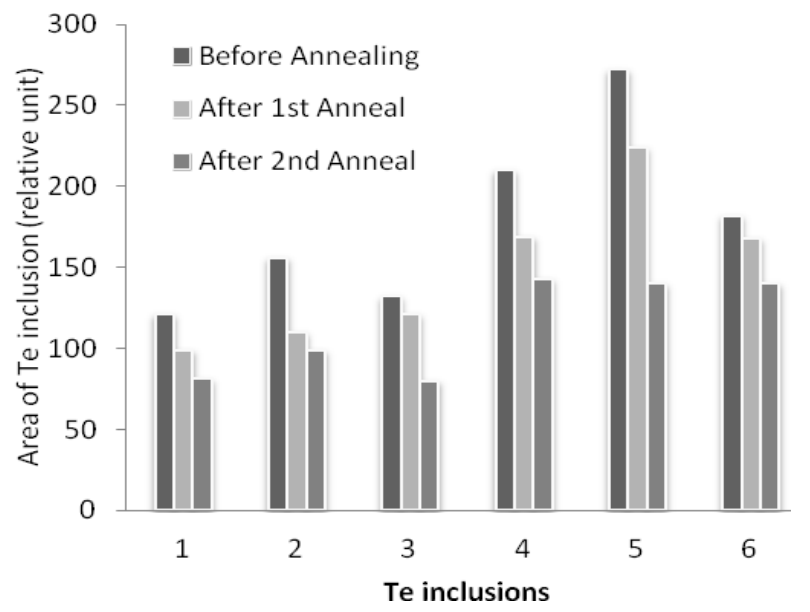

Fig. 2. Comparison of size reductions for six selected Te inclusions in the two annealing cycles. The areas were calculated using NIS-Elements Nikon imaging software.

In each annealing cycle, there are reductions in the sizes of the Te inclusions as indicated by the infrared images in Fig. 1. In addition to size reduction (see Fig. 2), the Te inclusions also migrate towards the high-temperature side of the sample. The migration of Te inclusions is clearly shown in Fig. 3 for the following annealing parameters: $700{ }^{\circ} \mathrm{C} \mathrm{CdZnTe}$ annealing temperature, Cadmium temperature at $650{ }^{\circ} \mathrm{C}, 30$ minutes annealing time, and temperature gradient of $10{ }^{\circ} \mathrm{C} / \mathrm{cm}$.

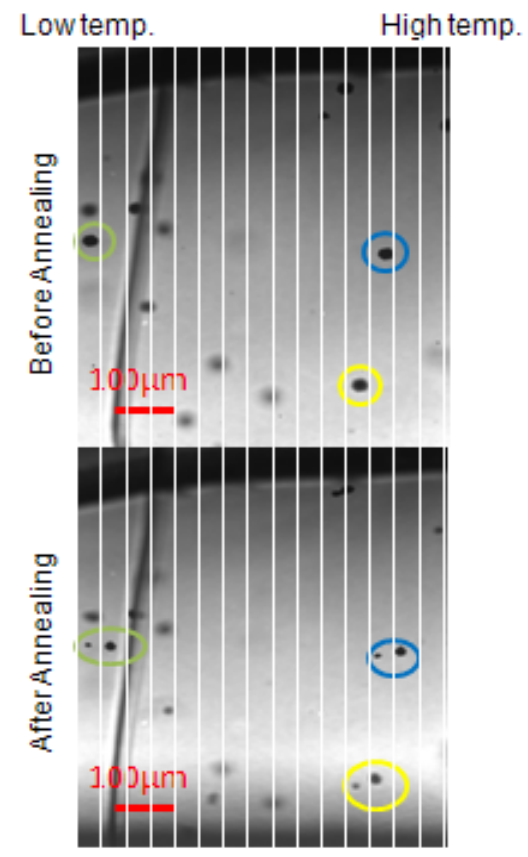

Fig. 3. Migration of Te inclusions towards the high-temperature in thermal gradient post-growth annealing of a CdZnTe crystal under Cd vapor overpressure.

Figure 2 shows the comparison of the size reductions for six selected Te inclusions in the two annealing cycles shown in Fig 1, with the areas calculated using NIS-Elements Nikon imaging software. The percentage reductions are shown in 
Table I. Figures 1 and 3 show that for most of the Te inclusions, an inclusion separates into two with the lager portion migrating towards the high-temperature side of the sample, leaving the smaller portion behind.

TABle I. Percentage Reduction of Te inclusions

\begin{tabular}{llll}
\hline Te inclusion & $\begin{array}{l}\text { Size before } \\
\text { annealing }\end{array}$ & $\begin{array}{l}\text { Reduction after } \\
\text { first annealing }\end{array}$ & $\begin{array}{l}\text { Reduction after } \\
\text { second annealing }\end{array}$ \\
\hline 1 & 121 & $18 \%$ & $18 \%$ \\
2 & 156 & $29 \%$ & $10 \%$ \\
3 & 132 & $8 \%$ & $34 \%$ \\
4 & 210 & $20 \%$ & $15 \%$ \\
5 & 272 & $18 \%$ & $38 \%$ \\
5 & 182 & $8 \%$ & $17 \%$ \\
\hline
\end{tabular}

\section{CONCLUSION}

Our studies have shown that annealing CdZnTe crystals under $\mathrm{Cd}$ vapor overpressure and in vacuum at $600{ }^{\circ} \mathrm{C}$ for 45 minutes at a temperature gradient of $10{ }^{\circ} \mathrm{C} / \mathrm{cm}$ showed significant reduction in the size of $\mathrm{Te}$ inclusions. The reduction in sizes ranges from $8 \%$ to $38 \%$. In addition, for most of the Te inclusions, an inclusion separates into two with the lager potion migrating towards the high-temperature side of the sample, leaving the smaller portion behind.

\section{REFERENCES}

[1] L. Verger, J. P. Bonnefoy, F. Glasser, and P. Ouvrier-Buffet, "New developments in CdTe and CdZnTe detectors for X and $\gamma$-ray application,” Journal of Electronic Materials, vol. 26, no.6, pp. 738-744, 1997.
[2] R. B. James, T. E. Schlesinger, J. C. Lund, and M. Schieber, "Semiconductors for room temperature nuclear detector applications," Academic Press, San Diego, vol. 43, 1995.

[3] T. E. Schlesinger, J. E. Toney, H. Yoon, E. Y. Lee, B. A. Brunett, L. Franks, R. B. James, " Cadmium zinc telluride and its use as a nuclear radiation detector material,”Material Science and Engineering, vol. 32, pp. 103-189, 2001.

[4] Stefano Del Sordo, Leonardo Abbene, Ezio Caroli, Anna Maria Mancini, Andrea Zappettini and Pietro Ubertini, "Progress in the Development of CdTe and CdZnTe Semiconductor Radiation Detectors for Astrophysical and Medical Applications,” Sensors, vol. 9, pp. 34913526, 2009.

[5] C. Scheiber, "CdTe and CdZnTe detectors in nuclear medicine," Nuclear Instruments and Methods in Physics Research A, vol. 448, pp. 513-524, 2000.

[6] L. Verger, M. Boitel, M.C. Gentet, R. Hamelin, C. Mestais, F. Mongellaz, J. Rustique, G. Sanchez, "Characterization of CdTe and CdZnTe detectors for gamma-ray imaging applications," Nuclear Instruments and Methods in Physics Research A, vol. 458, pp. 297-309, 2001.

[7] O. Limousin, "New trends in CdTe and CdZnTe detectors for X- and gamma-ray applications," Nuclear Instruments and Methods in Physics Research A vol. 504, pp. 24-37, 2003.

[8] A. E. Bolotnikov, G. S. Camarda, G. A. Carini, Y. Cui, K. T. Kohman, L. Li, M. B. Salomon, R. B. James,"Performance-Limiting Defects in CdZnTe Detectors," IEEE Transactions on Nuclear Science, vol. 54, no. 4, Pp.821-827, 2007.

[9] L. Wanwana, C. Zechunb, Z. Binb, Z. Fengb, L. Hongtaob, S. Wenbinb, M. Jiahuab, S. Kanga, "Study on the effect of Cd-diffusion annealing on the electrical properties of CdZnTe," Journal of Crystal Growth, vol. 292, no.1, pp. 53-61, 2006.

[10] P. Fochuk, R. Grill, O. Kopach, A. E. Bolotnikov, E. Belas, M. Bugar, G. Camarda, W. Chan, Y. Cui, A. Hossain, K. H. Kim, I. Nakonechnyi, O. Panchuk, G. Yang, R. B. James, "Elimination of Te Inclusions in $\mathrm{Cd}_{1-\mathrm{x}} \mathrm{Zn}_{\mathrm{x}} \mathrm{Te} \quad$ Crystals by Short-term Thermal Annealing," IEEE Transactions on Nuclear Science, vol. 59, no. 2, pp.256-263, 2012. 